\title{
Topographical analysis of fractured surface roughness of macro fiber reinforced concrete and its correlation with flexural toughness
}

\author{
Yining DING ${ }^{a^{*}}$, Wei ZENG ${ }^{\mathrm{a}}$, Qing WANG ${ }^{\mathrm{b}}$, Yulin ZHANG ${ }^{\mathrm{c}}$ \\ ${ }^{a}$ State Key Laboratory of Coastal and Offshore Engineering, Dalian University of Technology, Dalian 116024, \\ China \\ ${ }^{b}$ State Grid Henan Economic Research Institute, Zhengzhou 450000, China \\ ${ }^{c}$ Centre of Mathematics, University of Minho, Braga 4700-052, Portugal
}

\begin{abstract}
Macro fibers reinforcement is considered to be an effective way to improve the flexural toughness of the concrete. With growing public interest in wide-spread use of fiber reinforced concrete (FRC), the need for understanding and evaluating micro fiber reinforcement mechanism is on the rise. In this study, concretes were reinforced by various dopant amounts of macro polypropylene (PP) fiber or steel fiber (SF) or their mixtures, topographical analysis was applied on a fractured concrete surface by using a custom-built 3-D laser scanning equipment, and the tested surface was fractured by using a three-point bending beam test. The topographical analysis results were evaluated quantitatively by roughness parameters of roughness number $(R N)$, fractal dimension $(D)$, standard deviation of height distribution $\left(\sigma_{z}\right)$, and arithmetic mean deviation of the surface topography $\left(H_{a}\right)$. Multivariate analysis suggests the most effective of roughness number $(R N)$ for evaluating the roughness of fractured surface. Furthermore, the $R N$ of fractured surface was further correlated to the flexural toughness of the concrete, the relation between the fractured concrete surface roughness $(R N)$ and flexural toughness follows an exponential function, which can be employed to quickly estimate its roughness of fractured surface by flexural toughness of the FRC. In conclusion, from the developed topographical analysis method, the hybrid fibers reinforced concrete shows the
\end{abstract}


most significant improvement of the flexural toughness of the concrete, which suggests hybrid fiber reinforcement shall be a future solution for commercialization of the FRC in terms of high toughness and high durability.

Keywords: Fractured surface; Roughness parameter; Flexural toughness; Multivariate analysis; 3-D laser scanning equipment

\section{Introduction}

Concrete is heterogeneous, porous and rough composite material with complicated micro-structures and meso-structures. The previous studies have demonstrated that concrete behavior is mainly determined by the micro-structural heterogeneity. The heterogeneity is produced by the property and proportion of different materials in the concrete and causes the initial local defects such as the micro-cracks and voids. Under the mechanical loading, the voids and micro-cracks propagate and become the macro-cracks ${ }^{[1,2]}$, and the type of macro-cracks propagation dominates correspondingly the type of failure ${ }^{[3,4]}$. During all reinforced concretes service life, they work with cracks due to the low tensile capacity of concrete. While the existence of cracks can obviously accelerate the degradation of concrete, due to the intrusion of water inside the concrete with deleterious substances such as chloride and sulphate ions. Moreover, when the crack width is the same, the ease with which fluid penetrates into concrete depends mainly on the fractured surface topography of concrete ${ }^{[5,6]}$. As such, the durability of concrete is relevant to the fractured surface topography. Fiber reinforced concrete (FRC) is an increasingly popular construction material during recent years. The short randomly distributed fibers in the concrete matrix can address some of the concerns related to concrete brittleness, and have long been recognized as an effective way to increase the roughness of fractured surface of concrete and reduce water permeability of fractured concrete $^{[6]}$. However, the investigation on the effects of fiber on the topography of fractured surface, especially the effects of fiber type and fiber content on the roughness of fractured surface are still very limited. 
In recent decades, some researchers have studied the topography characteristic of the cement-based materials employing some instrumental techniques. Different methods have the similar goal that is to acquire the information of fractured surface topography and reconstruct the fractured surface of concrete. The current instruments include focused ion beam ${ }^{[7]}, \mathrm{X}$-ray computed tomography ${ }^{[8]}$, scanning electron microscopy ${ }^{[9-12]}$ and confocal microscopy ${ }^{[9,13-17]}$. While the size of the corresponding specimens of these instruments is relatively small (approximately 1-30000 $\mu \mathrm{m}$ ) and cannot be suitable for concrete materials. We have a custom-built 3-D laser scanning equipment, and it can be applied to investigate the fractured surface topography of concrete in meso-scale and macro-scale without restriction on the specimen size.

In order to quantify the surface roughness of cement-based materials, some roughness parameters have been calculated by the information of fractured surface topography and employed to reflect the topography of material surface in previous investigations, i.e. roughness number ${ }^{[2,16,18-22]}$ and fractal dimension ${ }^{[2,4,16,17,23,24]}$, standard deviations of height distributions ${ }^{[12,25]}$, arithmetic mean deviation of the surface topography ${ }^{[15,26]}$, etc. These roughness parameters force on the global character of material surface topography, while it is worth noting that different roughness parameters maybe have different results in quantifying the roughness of the surface. The investigations on selecting the most effective roughness parameter for analyzing the roughness of fractured surface are still very rare.

As a result of crack propagation, the fractured surface topography may reveal the corresponding failure behavior ${ }^{[21,27]}$. Some investigations have been conducted to analyze the relationship between the fractured surface topography and the mechanical behavior of plain concrete. Issa et al. ${ }^{[4]}$ investigated the correlation between fracture properties and the roughness of fracture surface using the slit-island method. Ficker et al. ${ }^{[18]}$ analyzed the relationship between the roughness of the fractured surface and the compression strength of hydrated cement pastes with the w/c from 0.4 to 1.0 by confocal microscopy. Erdem et al. ${ }^{[2]}$ studied the influence on the fracture-related properties in different types of concrete having different coarse aggregate characteristics. Their results showed that the mechanical behavior of concrete correlated very well with the roughness of fractured surface. 
While the review of literatures indicates that the topographical analysis could be used to evaluate the surface roughness of the concrete, and the fractured surface roughness of the concretes could be correlated to their mechanical properties. When the quantitative relationships are obtained, once the mechanical behavior of concrete are known, and then the roughness of fractured surface can be calculated. Meanwhile, some investigations ${ }^{[6,28-30]}$ have verified the relationships between roughness and permeability of crack. Moreover, the tests and methods of mechanical behavior of concrete have been maturely developed. Compared to the durability ( gas/ water permeability) tests, the mechanical tests show the advantages such as simplicity, accuracy and efficiency. If the durability properties of concrete maybe indirectly be estimated by means of the mechanical behavior of concrete, the time and cost of test for measuring the durability properties of concrete will be greatly saved and its accuracy can be obviously improved. However, there is lack of investigations on quantitative analysis of such correlations. In this paper, 3 reinforcements (polypropylene fiber reinforced concrete (PFRC), steel fiber reinforced concrete (SFRC) and hybrid fiber reinforced concrete (HFRC)) and total 9 different proportions were investigated. After the three-point bending test, the fractured surface was scanned by a custom-built 3-D laser scanning equipment, and the topographical features of the fractured concrete surface were converted to be explained by an effective roughness parameter, which was used for a quantitative evaluation of flexural toughness of FRC.

\section{Experimental program}

\subsection{Materials}

The P.O 42.5R Portland cement (in line with Chinese Standard GB175-2007 [31], P.O stands for Ordinary Portland Cement) was used to prepare the FRC. The fly ash, with a specific gravity of $2.0 \mathrm{~g} / \mathrm{cm}^{3}$ was used as an admixture. The fine aggregate was the quartz sand with a fineness modulus of 2.6. The coarse aggregate was the natural crashed gravels with maximum size of $10 \mathrm{~mm}$. The properties and geometry of macro PP fiber and steel fiber are listed in Table 1 and Fig. 1. The mix design of concrete without fiber reinforcement is listed in Table 2. According to the ASTM Standard C143 ${ }^{[32]}$ and C231 ${ }^{[33]}$, the slump and air 
content of fresh FRC were tested and listed in Table 3. With the increase of fiber content, a decrease in the slump and an increase in the air content of concrete paste were observed, respectively. And the 28 days compression test showed almost identical compressive strength of FRC specimens.

Table1 Properties of the fibers

\begin{tabular}{cccccccc}
\hline Type & $\begin{array}{c}\text { Shape of } \\
\text { fiber }\end{array}$ & $\begin{array}{c}\text { Length } \\
(\mathrm{mm})\end{array}$ & $\begin{array}{c}\text { Diameter } \\
(\mathrm{mm})\end{array}$ & $\begin{array}{c}\text { Aspect } \\
\text { ratio }\end{array}$ & $\begin{array}{c}\text { Tensile } \\
\text { strength }\end{array}$ & $\begin{array}{c}\text { Elastic modulus } \\
(\mathrm{GPa})\end{array}$ & Number \\
& & & & $(\mathrm{MPa})$ & \\
\hline $\begin{array}{c}\text { Polypropylene } / \mathrm{kg}) \\
\text { fiber }\end{array}$ & Straight & 45 & 0.75 & 60 & 490 & 3.9 & $5.76 \times 10^{4}$ \\
Steel fiber & Hooked-end & 35 & 0.55 & 65 & 1150 & 200 & $1.45 \times 10^{4}$ \\
\hline
\end{tabular}

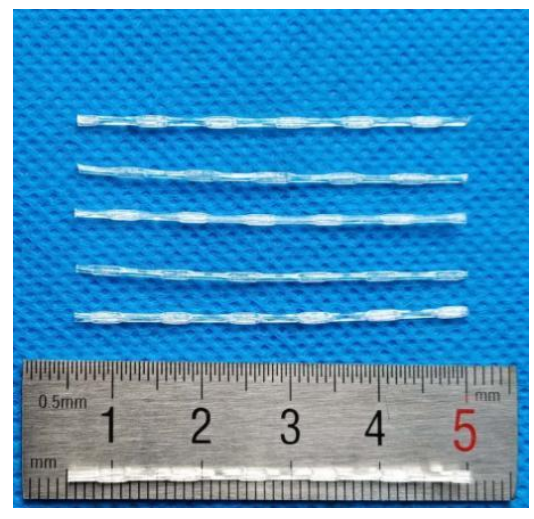

(a) Macro polypropylene fiber

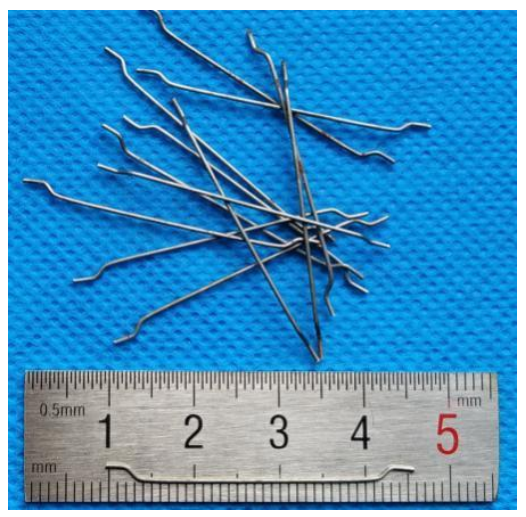

(b) Steel fiber

Fig.1. Geometry of fibers

Table 2 Mix proportion of plain concrete $\left(\mathrm{kg} / \mathrm{m}^{3}\right)$

\begin{tabular}{lcccc}
\hline & Fine aggregate & Coarse aggregate & \\
Cement & Fly ash & & Water & Superplasticizer \\
& & $(0-5 \mathrm{~mm})$ & $(5-10 \mathrm{~mm})$ & \\
\hline
\end{tabular}




\begin{tabular}{llllll}
\hline 390 & 155 & 822 & 848 & 272.5 & 5.5 \\
\hline
\end{tabular}

Table 3 Mix proportions of concrete mixes.

\begin{tabular}{|c|c|c|c|c|c|}
\hline $\begin{array}{c}\text { Mixture } \\
\text { ID }\end{array}$ & Steel fiber & Polypropylene fiber & $\begin{array}{l}\text { Slump } \\
(\mathrm{mm})\end{array}$ & $\begin{array}{c}\text { Air content } \\
(\%)\end{array}$ & $\begin{array}{c}\text { Compressive } \\
\text { strength } \\
\text { (MPa) }\end{array}$ \\
\hline $\mathrm{NC}$ & - & - & 195 & 1.9 & 37.3 \\
\hline PP2.3 & - & $2.3 \mathrm{~kg} / \mathrm{m}^{3}(0.25 \mathrm{vol} . \%)$ & 190 & 2.1 & 36.5 \\
\hline PP4.6 & - & $4.6 \mathrm{~kg} / \mathrm{m}^{3}(0.5 \mathrm{vol} . \%)$ & 177 & 2.3 & 35.4 \\
\hline PP6.9 & - & $6.9 \mathrm{~kg} / \mathrm{m}^{3}(0.75 \mathrm{vol} . \%)$ & 175 & 2.7 & 37.5 \\
\hline SF20 & $20 \mathrm{~kg} / \mathrm{m}^{3}(0.25 \mathrm{vol} . \%)$ & - & 170 & 2.5 & 41.7 \\
\hline SF40 & $40 \mathrm{~kg} / \mathrm{m}^{3}(0.5 \mathrm{vol} . \%)$ & - & 135 & 2.8 & 35.4 \\
\hline SF60 & $60 \mathrm{~kg} / \mathrm{m}^{3}(0.75 \mathrm{vol} . \%)$ & - & 115 & 3.3 & 34.1 \\
\hline SF20PP2.3 & $20 \mathrm{~kg} / \mathrm{m}^{3}(0.25 \mathrm{vol} . \%)$ & $2.3 \mathrm{~kg} / \mathrm{m}^{3}(0.25 \mathrm{vol} . \%)$ & 157 & 3.2 & 37.2 \\
\hline SF40PP2.3 & $40 \mathrm{~kg} / \mathrm{m}^{3}(0.5 \mathrm{vol} . \%)$ & $2.3 \mathrm{~kg} / \mathrm{m}^{3}(0.25 \mathrm{vol} . \%)$ & 130 & 4.0 & 38.5 \\
\hline
\end{tabular}

\subsection{Test specimens}

The beam shape specimens used in this study were cast into steel moulds $(100 \times 100 \times 400$ $\mathrm{mm}^{3}$ ). The specimens were demoulded after $24 \mathrm{~h}$. Afterwards they were transferred to a moist curing room and stored at $20^{\circ} \mathrm{C}$ and relative humidity over $90 \%$ for 28 days. Before the three-point flexural test, each beam was cut to obtain a $10 \mathrm{~mm}$ depth and $3 \mathrm{~mm}$ width notch. Three identical specimens were prepared from the same mixture proportion. 


\subsection{Flexural test}

According to RILEM Standard TC162-TDF ${ }^{[34]}$, the flexural performance of the beam concrete was tested on a setup of MTS Landmark ${ }^{\circledR}$ test system. The schematic of testing set-up is shown in Fig. 2. All the specimens were tested on a span of $300 \mathrm{~mm}$. The flexural test was determined by the deformation-controlled experiment. A close loop test machine was used and the deformation rate of the mid-span was $0.2 \mathrm{~mm} / \mathrm{min}$ until the specified end point deflection of $3.5 \mathrm{~mm}$ was reached. Two linear variable differential transformers (LVDTs) were applied on the front and back sides for measuring the deflection of mid-span. The IMC Intelligence Data Collecting System was used to collect the experimental data in real time. The load-deflection curves were employed to evaluate the flexural toughness of FRC.
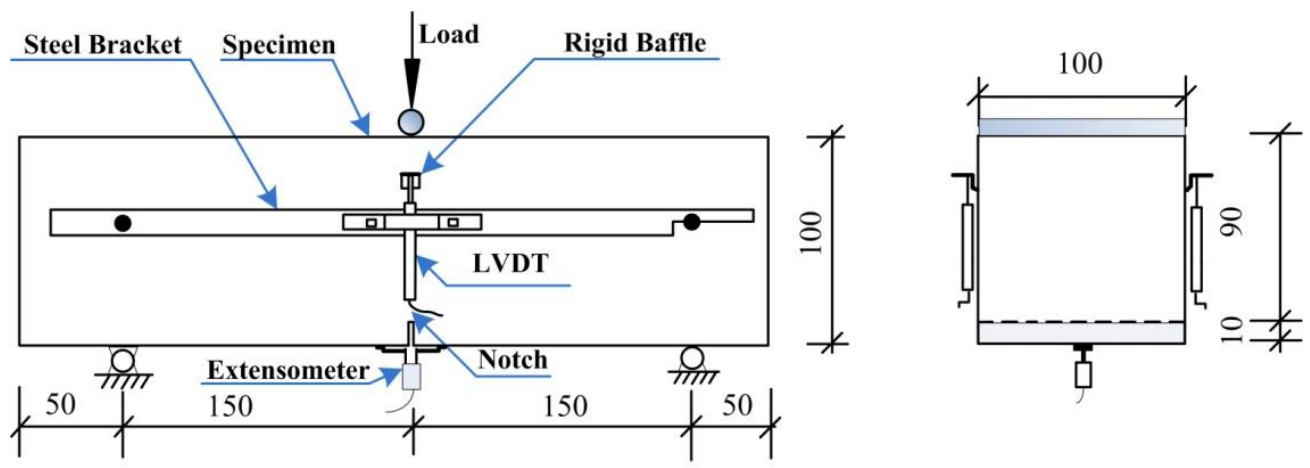

Unit: $\mathbf{m m}$

Fig. 2. Schematic description for the testing set-up.

\subsection{Acquisition of the surface data}

After the flexural test, the specimens were split into two parts along the crack and the connected fibers were cut off to expose the fractured surface. Later on, the custom-built 3-D laser scanning equipment was used to obtain the topographical information of the fractured surface (see Fig. 3). The 3-D laser scanning equipment was a non-contact device which enables to obtain the $\mathrm{x}, \mathrm{y}$ and $\mathrm{z}$ coordinates of the points on the fracture surface and it consisted of the computer, a control system, a data acquisition system, three laser sensors, a power system of laser sensors and a profilometer. Moreover, the laser sensors provided an accuracy of $7 \mu m$. The movement of the profilometer with laser sensors was automatically controlled according to a preprogrammed scanning path (see Fig. 4 ). The vertical projection 
area of scanning region was $100 \times 90 \mathrm{~mm}^{2}$.

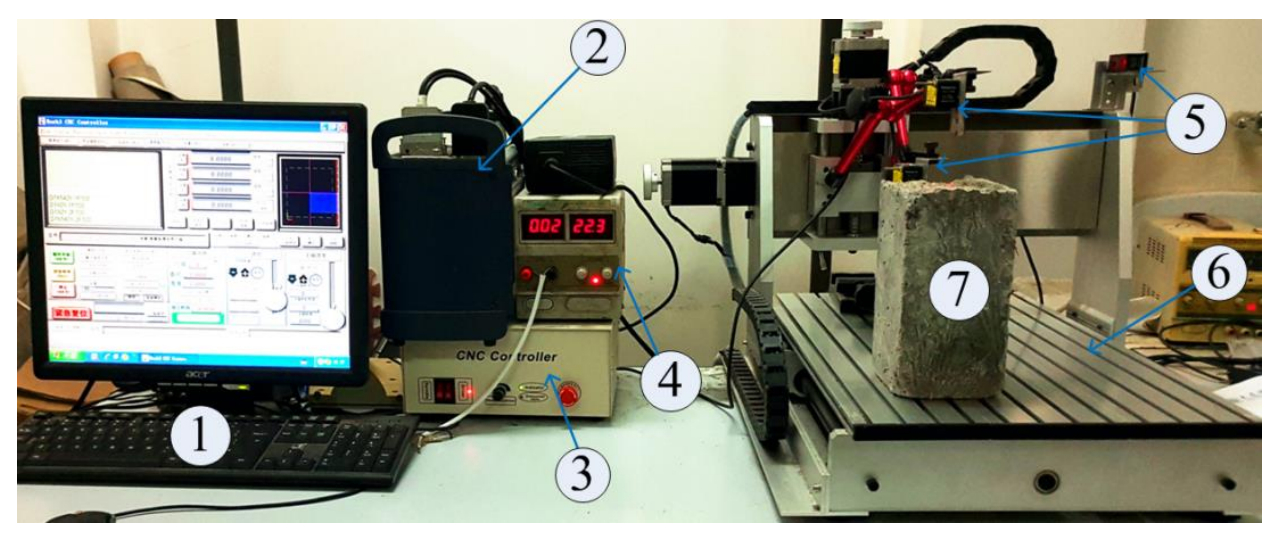

Fig. 3. Experimental set-up of the 3-D laser scanning equipment (modified from the published design of the set-up in ${ }^{[6]}$ )

1) PC; 2) Data acquisition system; 3) Control system; 4) Power system of laser sensors; 5) Laser sensors; 6) Profilometer; 7) Specimen.

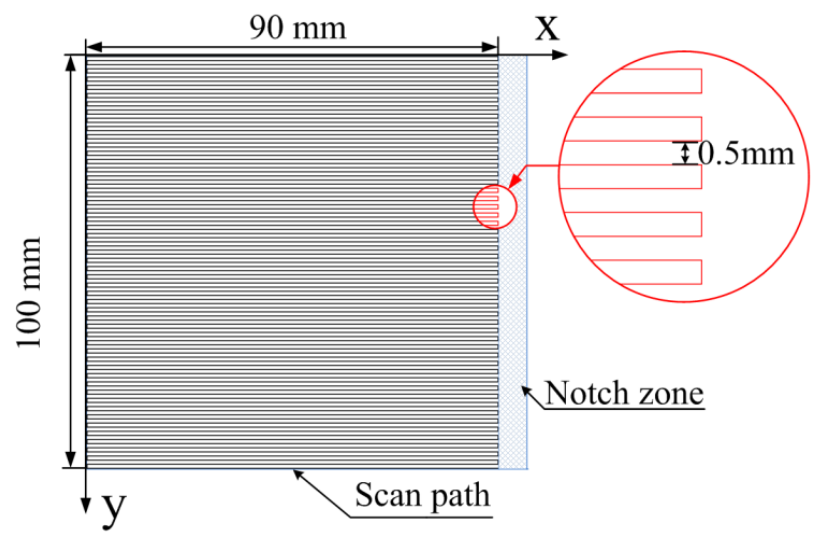

Fig. 4. Scanning path

\subsection{Roughness parameters}

According to the topographic data collected from the fractured surface, four roughness parameters can be calculated, which are intended to be employed to evaluate the roughness of FRC fractured surface. They are listed as follows: 


\subsubsection{Roughness number}

The roughness number $(R N)$ can be extracted from the topographical image (see Fig. 5). The left part is "wire" model of the reconstructed fractured surface, and the right part is the magnified view of one element in the "wire" model. The nominal area $S_{o}$ is the vertical projection of the surface area $S_{t}(\Delta)$ of fractured surface on the horizontal X-Y plane. The $\Delta$ is the size of the element. The number of elements in surface area $S_{t}(\Delta)$ is $N(\Delta)$. The surface area $S_{i, j}$ of each element is divided into two triangles in an element, their surface areas $\left(S_{a}\right.$ and $S_{b}$ ) are calculated according to the Heron's formula. The roughness number $R N(\Delta)$ can be calculated by Eq. (1)-(2) :

$$
\begin{gathered}
S_{t}(\Delta)=\sum_{i, j=1}^{N(\Delta)} S_{i, j}=\sum_{i, j=1}^{N(\Delta)}\left(S_{a}+S_{b}\right) \\
R N(\Delta)=\frac{S_{t}(\Delta)}{S_{o}}
\end{gathered}
$$

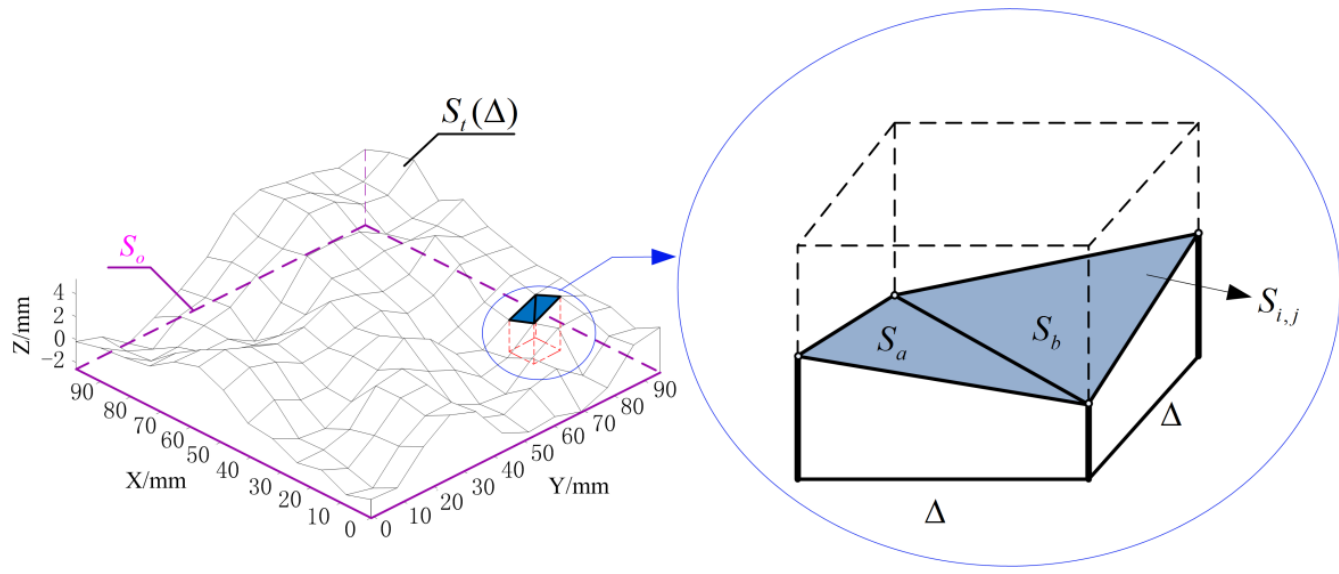

Fig. 5. Schematic view of fractured surface topography

\subsubsection{Fractal dimension calculated by box-counting method}

It is known that the fractured surfaces exhibit fractal behavior ${ }^{[28]}$, and the fractal dimension can be employed to estimate the roughness of fractured surface. The box-counting method is a widely accepted approach to estimate the fractal dimension. The 
three-dimensional elements can be used to cover the irregular fractured surface (see Fig. 6). The size $\delta$ of element and the roughness of fractured surface determine the number of elements $N(\delta)^{[35]}$.

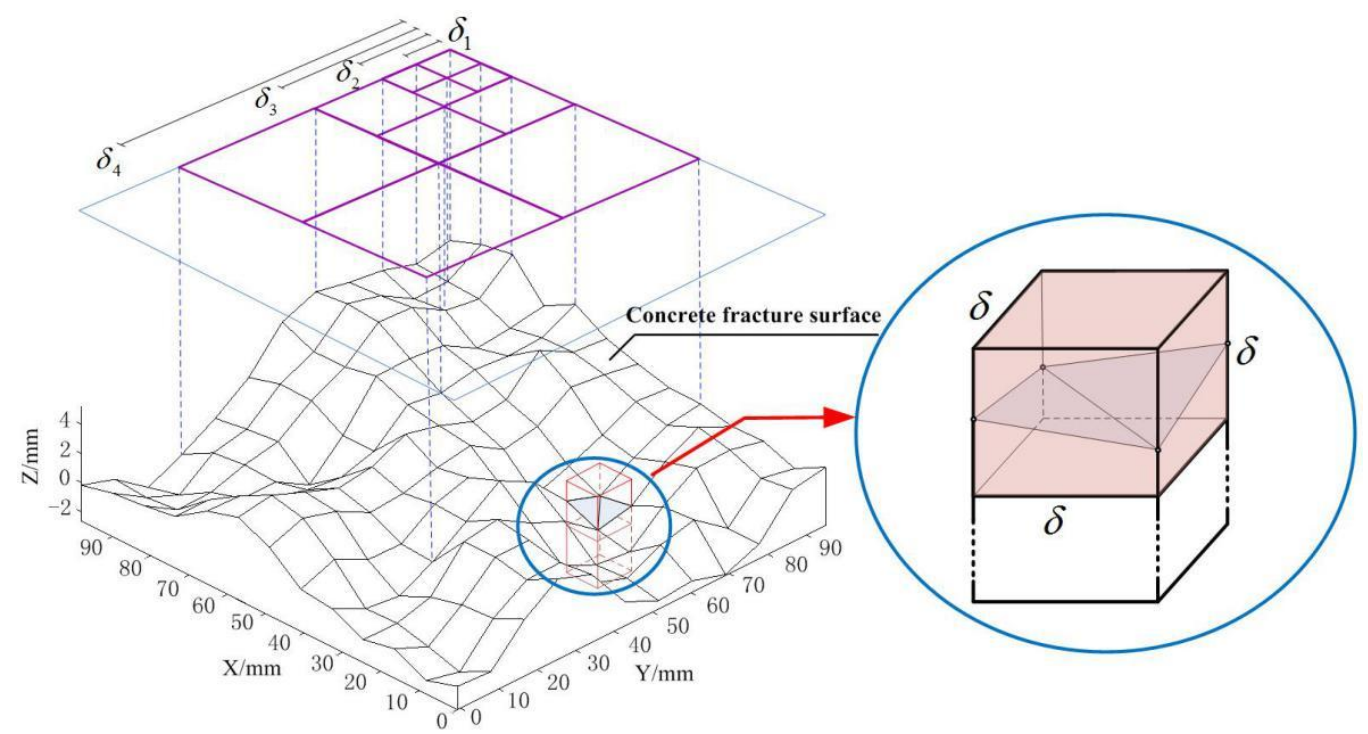

Fig. 6. Schematic view of the cubic covering method

As the size $\delta$ of element is changed, the number of elements $N(\delta)$ also changes, and the fractal dimension can be evaluated by the variation ratio of the number $N(\delta)$ of three-dimensional elements ${ }^{[26]}$. The relation between $N(\delta)$ and $\delta$ follows the power function in Eq. (4) ${ }^{[35]}$ :

$$
N(\delta)=F \delta^{-D}
$$

where $F$ is a constant determined from experimental measurement. $D$ is the fractal dimension calculated by box-counting method.

\subsubsection{Standard deviation of height distribution}


Every sample has its unique height distributions of z-coordinates of measured points on the scanning area ${ }^{[12]}$, it means that the standard deviation $\sigma_{z}$ of height distribution can be used to characterize the dispersion of z-coordinates and then indirectly indicate the roughness of fractured surface. The standard deviation $\sigma_{z}$ of height distribution can be evaluated from Eq. (5):

$$
\sigma_{z}=\sqrt{\frac{\sum_{i=1}^{N}\left(z_{i}-\bar{z}\right)^{2}}{N}}
$$

where $\bar{z}$ is the average value of z-coordinates of all measured points on the scanning area, $N$ is the number of measured points.

\subsubsection{Amplitude parameter}

Arithmetic mean deviation of the surface topography $\left(H_{a}\right)$ is given as an amplitude parameter to characterize the fractured surface. It describes the deviation of surface heights relative to the mean plane. It is calculated in Eq. (6) ${ }^{[15]}$ :

$$
H_{a}=\frac{1}{L \cdot M} \cdot \iint_{(L M)}|z(x, y)-\bar{z}| d x d y
$$

where $z(x, y)$ is the function of topographical image, $\bar{z}$ is the mean plane of the z-coordinates of all measured points, $L$ and $M$ represent the sides of the projection area in the X-Y plane .

\section{Results and discussion}

\subsection{Flexural properties}

The load-deflection curves of the specimens (with or without fiber reinforcement) are shown in the Fig. 7, the three-point bending test followed the RILEM TC162-TDF ${ }^{[34]}$. The flexural strength, ultimate load, energy absorption, equivalent flexural strength and fiber 
numbers on the fractured surfaces are listed in Table 4, where the values are average of three specimens.

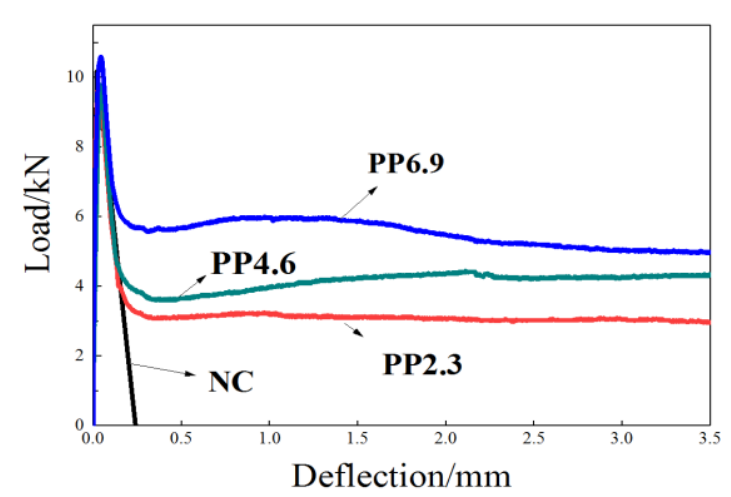

(a)

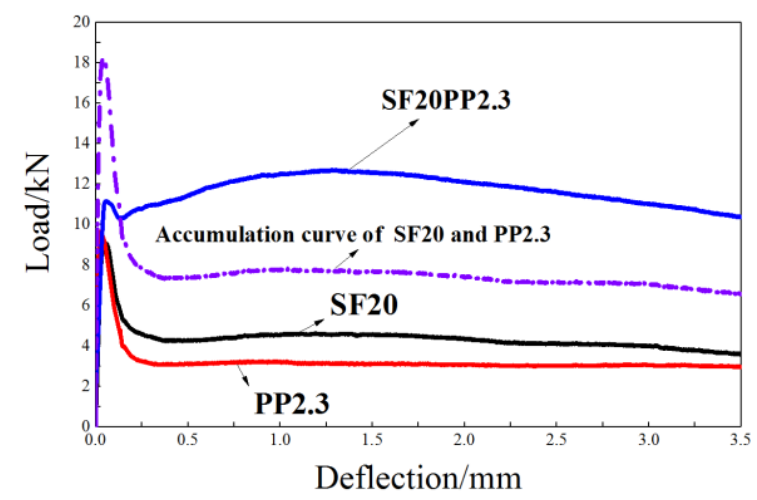

(c)

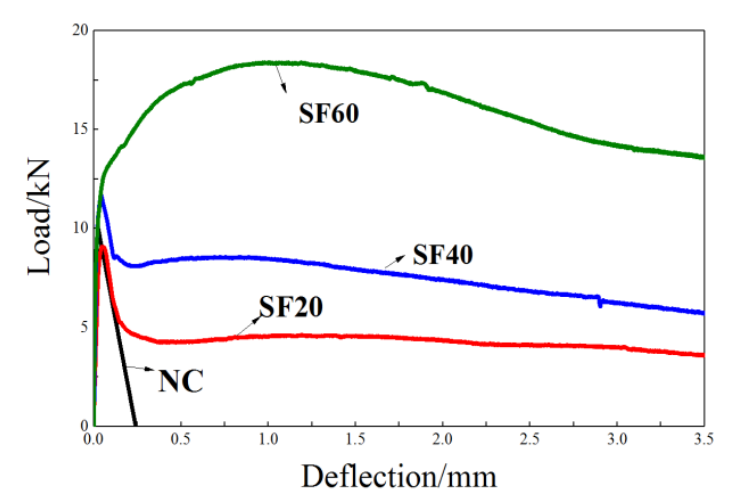

(b)

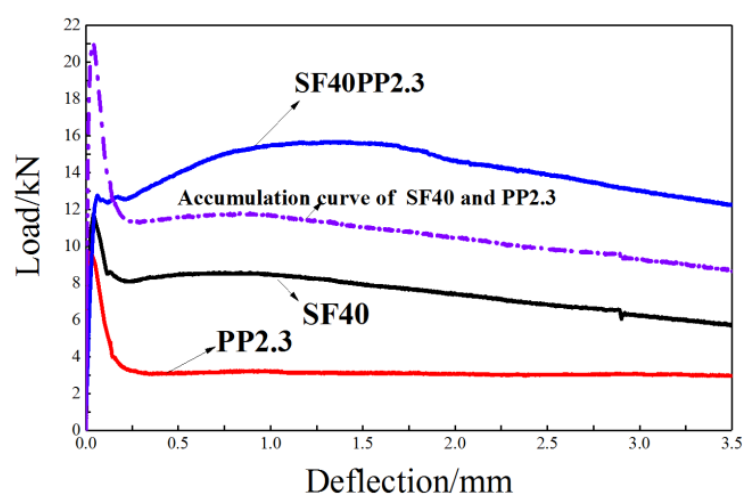

(d)

Fig. 7. Comparison of load-deflection curves of different specimens

(a) PFRC; (b) SFRC; (c) SF20PP2.3- PP2.3- SF20; (d) SF40PP2.3- PP2.3- SF40.

Table 4 Flexural strength, ultimate load and parameters of flexural toughness of different samples

\begin{tabular}{lcccccccccc}
\hline \multirow{2}{*}{ Specimens } & $\mathrm{F}_{\mathrm{L}}$ & $\mathrm{f}_{\mathrm{fct}, \mathrm{L}}$ & $\mathrm{F}_{\mathrm{u}}$ & $\mathrm{D}_{\mathrm{BZ}, 2}^{\mathrm{f}}$ & $\mathrm{f}_{\text {eq, } 2}$ & $\mathrm{~F}_{2}$ & $\mathrm{D}_{\mathrm{BZ}, 3}^{\mathrm{f}}$ & $\mathrm{f}_{\text {eq,3 }}$ & $\mathrm{F}_{3}$ & $\mathrm{~N}_{\mathrm{f}}$ \\
& $\mathrm{kN}$ & $\mathrm{MPa}$ & $\mathrm{kN}$ & $\mathrm{N} \cdot \mathrm{m}$ & $\mathrm{MPa}$ & $\mathrm{kN}$ & $\mathrm{N} \cdot \mathrm{m}$ & $\mathrm{MPa}$ & $\mathrm{kN}$ & \\
\hline $\mathrm{NC}$ & 10 & 5.6 & 10 & 0 & 0 & 0 & 0 & 0 & 0 & 0 \\
PP2.3 & 9.7 & 5.4 & 9.7 & 1.1 & 1.20 & 3.06 & 7.4 & 1.65 & 3.15 & 50.7 \\
& & & & & & & & & & \\
\hline
\end{tabular}




\begin{tabular}{|c|c|c|c|c|c|c|c|c|c|c|}
\hline PP4.6 & 9.8 & 4.5 & 9.8 & 1.4 & 1.53 & 3.34 & 9.7 & 2.16 & 3.71 & 108 \\
\hline PP6.9 & 10.6 & 5.9 & 10.6 & 2.3 & 2.51 & 5.85 & 13.9 & 3.10 & 5.47 & 169 \\
\hline SF20 & 9.1 & 5.1 & 9.1 & 2.0 & 2.23 & 5.63 & 11.3 & 2.52 & 5.30 & 60 \\
\hline SF40 & 11.4 & 6.4 & 11.9 & 4.3 & 4.82 & 9.51 & 25.3 & 5.63 & 7.75 & 125 \\
\hline SF60 & 12.4 & 6.9 & 18.4 & 9.1 & 10.12 & 19.25 & 45.1 & 10.03 & 14.91 & 199.3 \\
\hline SF20PP2.3 & 11.2 & 6.2 & 13 & 5.1 & 5.67 & 12.06 & 29.5 & 6.56 & 11.35 & 134.7 \\
\hline SF40PP2.3 & 12.3 & 6.8 & 15.7 & 6.2 & 6.89 & 14.86 & 36.2 & 8.04 & 13.55 & 194.3 \\
\hline
\end{tabular}

Note: $F_{L}(k N)$ is the maximum load in the interval of $0.05 \mathrm{~mm} ; f_{\mathrm{fct}, \mathrm{L}}$ is the flexural strength corresponding to $\mathrm{F}_{\mathrm{L}} ; \mathrm{D}_{\mathrm{BZ}, 2}^{\mathrm{f}}(\mathrm{N} \cdot \mathrm{m})$ and $\mathrm{D}_{\mathrm{BZ}, 3}^{\mathrm{f}}(\mathrm{N} \cdot \mathrm{m})$ are the energy absorption of the influence of fiber at the deflections of $\left(\delta_{\mathrm{L}}+0.65 \mathrm{~mm}\right)$ and $\left(\delta_{\mathrm{L}}+2.65 \mathrm{~mm}\right)$, respectively; $\mathrm{f}_{\mathrm{eq}, 2}$ and $\mathrm{f}_{\mathrm{eq}, 3}$ are the equivalent flexural tensile strengths by the deflections of $\left(\delta_{\mathrm{L}}+0.65 \mathrm{~mm}\right)$ and $\left(\delta_{\mathrm{L}}+2.65 \mathrm{~mm}\right)$, respectively; $\delta_{\mathrm{L}}$ is the deflection corresponds to the $F_{L}(\mathrm{~mm}) ; F_{2}$ and $F_{3}$ are the residual load at the deflections of $\left(\delta_{\mathrm{L}}+0.65 \mathrm{~mm}\right)$ and $\left(\delta_{\mathrm{L}}+2.65 \mathrm{~mm}\right), \mathrm{N}_{\mathrm{f}}$ is the number of fibers on the fractured surface, respectively.

A comparison of load-deflection of PFRC and SFRC beams is shown in Fig. 7 (a) and Fig. 7 (b), respectively. It can be seen:

1) The load bearing capacity of NC drops suddenly and the failure occurs just after the crack formation. For FRC, the load bearing capacity drops and then stabilizes at post-peak stage.

2) Fig. 7 (a) illustrates the comparison of load-deflection curves of PFRC beams with 2.3 $\mathrm{kg} / \mathrm{m}^{3}, 4.6 \mathrm{~kg} / \mathrm{m}^{3}$ and $6.9 \mathrm{~kg} / \mathrm{m}^{3}$ fiber contents, respectively.

a) Compared to the PP2.3, the equivalent flexural strength $f_{\text {eq, } 2}$ and $f_{\text {eq }, 3}$ of PP4.6 increase by $27.5 \%$ and $31 \%$, respectively, the equivalent flexural strength $f_{e q, 2}$ and $\mathrm{f}_{\text {eq,3 }}$ of PP6.9 increase by $109 \%$ and $88 \%$, respectively.

b) Compared to the PP2.3, the increment for the number of fibers on the fractured 
surfaces of PP4.6 and PP6.9 achieve about $113 \%$ and 233\%, respectively.

c) For the PP2.3, PP4.6 and PP6.9, the load bearing capacity increase slightly and then decrease gradually after the first drop, and then the load-deflection curves indicate less post-cracking flexural load than the cracking load, and exhibit the deflection softening behavior.

3) Fig. 7 (b) illustrates the comparison of load-deflection curves of SFRC beams with 20 $\mathrm{kg} / \mathrm{m}^{3}, 40 \mathrm{~kg} / \mathrm{m}^{3}$ and $60 \mathrm{~kg} / \mathrm{m}^{3}$ fiber contents, respectively.

a) Compared to the SF20, the equivalent flexural strength $f_{\text {eq, } 2}$ and $f_{\text {eq, } 3}$ of SF40 increase by $116 \%$ and $123 \%$, respectively, and the equivalent flexural strength $\mathrm{f}_{\text {eq, }}$ and $\mathrm{f}_{\text {eq, } 3}$ of SF60 increase by $354 \%$ and $298 \%$, respectively.

b) Compared to the SF20, the increment for the number of fibers on the crack surfaces of SF40 and SF60 achieve about 108\% and 232\%, respectively.

c) For SF20 and SF40, the deflection softening behavior is also observed. For SF60, after the first drop of load, the curve possesses a higher flexural load than the cracking load and exhibits the deflection hardening behavior.

From the discussion above, it can be seen that the addition amount of steel fiber of the SF40 and SF60 are 2 and 3 times of SF20, however, according to the fracture surface analysis, the number of fiber at fracture surfaces of SF40 and SF60 are 2.08 and 3.32 times higher than that of SF20. It can be inferred that the increase rate of the number of fibers on the crack surface is higher than the increase rate of fiber content with the increasing of fiber content, PFRC displays a similar behavior. In this case, there is much higher amount of fibers reinforcement at fracture surface of concretes with the increasing of fiber content, this leads to a significant improvement in the post-peak flexural behavior of PFRC and SFRC with increment of fiber content. Meanwhile, in comparison of the load-deflection curves with the same fiber content of macro PP fibers and steel fibers in Fig. 7 (a) and Fig. 7 (b), SFRC exhibits better flexural behavior over the entire deflection range than that of PFRC.

Fig. 7 (c) and Fig. 7 (d) illustrate the influence of hybrid fibers (PP fiber + steel fiber) on 
the load-deflection curves of concrete subjected to bending.

From Fig. 7 (c) and Fig. 7 (d) and Table 4, it can be seen:

1) The purple lines in Fig. 7 (c) and Fig. 7 (d) are accumulated curves of the corresponding mono fiber reinforced beams. Crossing the deflection of $0.2 \mathrm{~mm}$, the load bearing capacity of HFRC (SF20PP2.3 / SF40PP2.3) are higher than the sum of the load bearing capacity of mono fiber reinforced beams (SF20+PP2.3 / SF40+PP2.3).

2) Compared to the sum of the equivalent flexural strength values of PP2.3 and SF20, the equivalent flexural strength $\mathrm{f}_{\text {eq, } 2}$ and $\mathrm{f}_{\text {eq, } 3}$ of SF20PP2.3 increase by $65 \%$ and $57 \%$, respectively. Meanwhile, compared to the sum of the equivalent flexural strength values of PP2.3 and SF40, the increment for the equivalent flexural strength $\mathrm{f}_{\mathrm{eq}, 2}$ and $\mathrm{f}_{\mathrm{eq}, 3}$ of SF40PP2.3 achieve about $14 \%$ and $10 \%$, respectively.

3) Compared to the sum of the number of fibers on the fractured surface of PP2.3 and SF20, the number of fibers on the crack surface of SF20PP2.3 increases by about 22\%, and compared to the sum of the number of fibers on the fractured surface of PP2.3 and SF40, the increment for the number of fibers on the crack surface of SF40PP2.3 achieves about $11 \%$.

The discussion above demonstrates a positive synergistic effect of hybrid fibers on the post-peak behavior.

\subsection{Reconstruction of fractured surface}

Based on the topographical data of fractured surface obtained by 3-D laser scanning equipment, the fractured surfaces of concrete were reconstructed to gather topographical information of the surface. Fig. 8 demonstrates the reconstruction views of fractured surface and the height distribution histograms corresponding to the z-coordination of measured points of different samples. 


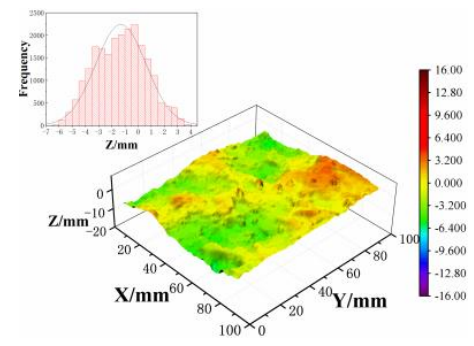

$\mathrm{NC}$

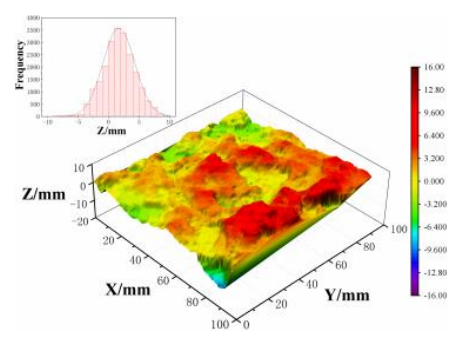

SF20PP2.3

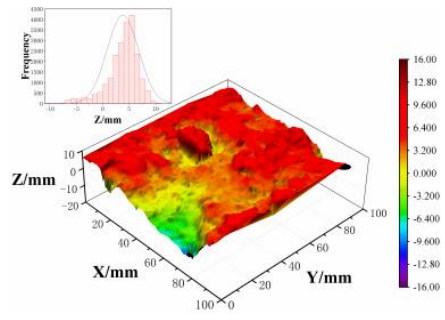

SF40PP2.3

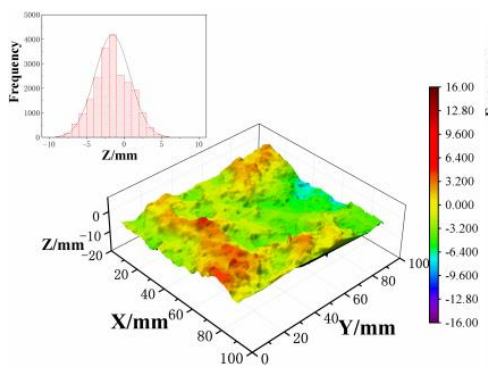

PP2.3

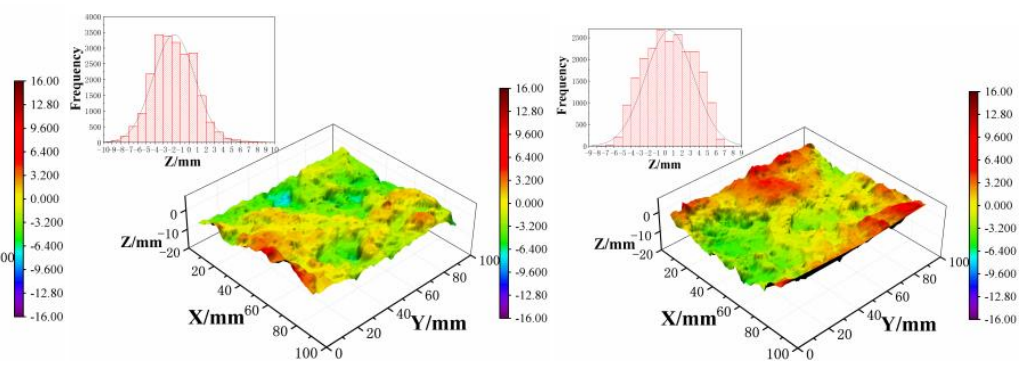

PP4.6

PP6.9

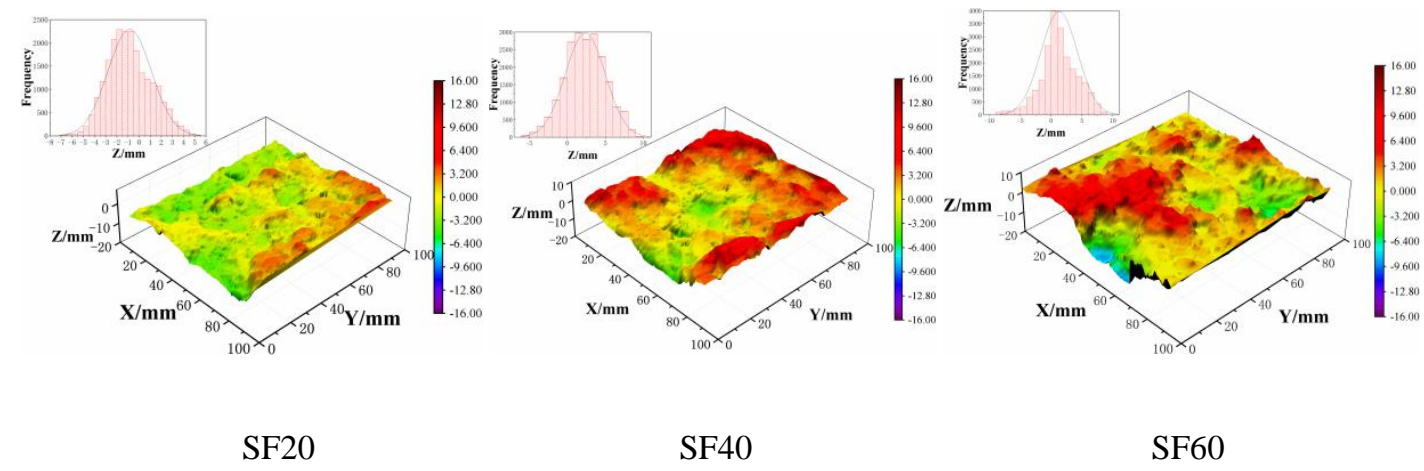

Fig. 8. Reconstruction views and height distribution histograms of fractured surface of different samples

From Fig. 8, it can be seen that the fractured surface of FRC is much rougher than that of NC. For FRC, the fractured surface becomes remarkably rough with increment of fiber content. Meanwhile, when the fiber content of FRC is the same ( for example, the fiber volume content of SF20PP2.3, PP4.6 and SF40 are 0.5 vol.\% and SF40PP2.3, PP6.9 and SF60 are 0.75 vol.\% ), HFRC is rougher than mono fiber reinforced concrete.

\subsection{Selection of the most effective roughness parameters for crack surface roughness}


In order to select the most effective parameter for quantifying the roughness of crack surface, the following analysis is performed.

Four roughness parameters, i.e. roughness number $(R N)$, fractal dimension $(D)$, standard deviation of height distribution $\left(\sigma_{z}\right)$ and arithmetic mean deviation of the surface topography $\left(H_{a}\right)$, were calculated and listed in Table 5.

Table 5 Roughness parameters of different samples

\begin{tabular}{|c|c|c|c|c|c|c|c|c|c|}
\hline \multirow{2}{*}{ Parameters } & \multirow[t]{2}{*}{$\mathrm{NC}$} & \multicolumn{3}{|c|}{ PFRC } & \multicolumn{3}{|c|}{ SFRC } & \multicolumn{2}{|c|}{ HFRC } \\
\hline & & PP2.3 & PP4.6 & PP6.9 & SF20 & SF40 & SF60 & SF20PP2.3 & SF40PP2.3 \\
\hline$R N$ & 1.20 & 1.23 & 1.58 & 1.74 & 1.47 & 1.89 & 1.98 & 1.96 & 2.04 \\
\hline$D$ & 2.068 & 2.076 & 2.117 & 2.125 & 2.082 & 2.124 & 2.149 & 2.143 & 2.157 \\
\hline$\sigma_{z}(\mathrm{~mm})$ & 2.173 & 2.250 & 2.542 & 2.587 & 2.411 & 2.805 & 2.994 & 2.896 & 3.384 \\
\hline$H a(m m)$ & 1.589 & 1.578 & 2.126 & 2.278 & 1.578 & 2.126 & 2.278 & 2.207 & 2.400 \\
\hline
\end{tabular}

In order to compare with the four roughness parameters in the same order of magnitude, each parameter is normalized ( the sum of all normalized values of each parameter equals to 1 ). Fig. 9 illustrates the comparison of the mean normalized values of the four roughness parameters of different samples. 


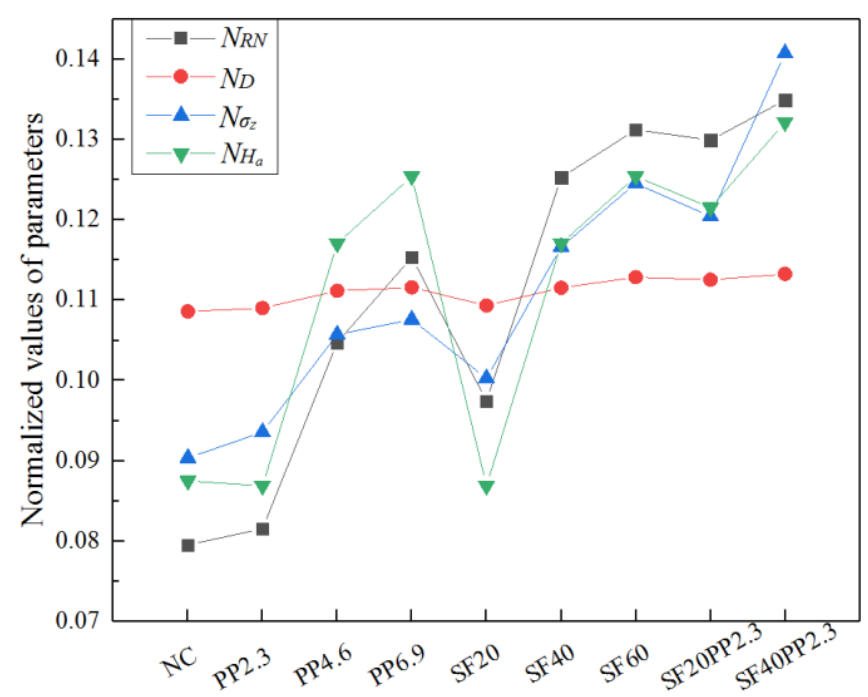

Fig. 9. Comparison of the four roughness parameters normalized values of different samples

(Nx stands for the normalized value of $\mathrm{x}$ parameter)

The increase addition of the fiber amount leads to the increase of roughness parameters ( $\left.R N, D, \sigma_{z}, H_{a}\right)$, similar trend could be observed for the specimens with all 3 fibers additions, as shown in Fig. 9.

This implies that all 4 parameters $\left(R N, D, \sigma_{z}, H_{a}\right)$ are equally useful for the evaluation of the fractured concrete surface. However, considering the significant principle, one significant parameter will be assessed for distinguishing the most representative roughness of fractured surface.

In order to signify the parameters, further analysis is carried out by dividing the nine samples into three groups, and this later-on is found to be useful to distinguish the roughness of fractured surface of different samples. Groups are listed in Table 6.

Table 6 Grouping the normalized roughness parameters of the surface roughness

\begin{tabular}{|c|c|c|c|c|c|c|c|c|c|}
\hline \multirow{2}{*}{$\begin{array}{l}\text { Roughness } \\
\text { parameters }\end{array}$} & \multicolumn{3}{|c|}{ Group1 } & \multicolumn{3}{|c|}{ Group2 } & \multicolumn{3}{|c|}{ Group3 } \\
\hline & $\mathrm{NC}$ & PP2.3 & SF20 & PP4.6 & PP6.9 & SF40 & SF20PP2.3 & SF60 & SF40PP2.3 \\
\hline
\end{tabular}




\begin{tabular}{ccccccccccc}
\hline$R N$ & 0.080 & 0.082 & 0.097 & 0.105 & 0.115 & 0.125 & 0.130 & 0.131 & 0.135 \\
$D$ & 0.109 & 0.109 & 0.109 & 0.111 & 0.112 & 0.112 & 0.113 & 0.113 & 0.113 \\
& & & & & & & & & \\
$\sigma_{z}$ & 0.090 & 0.094 & 0.100 & 0.106 & 0.108 & 0.117 & 0.120 & 0.125 & 0.141 \\
& & & & & & & & & \\
Ha & 0.088 & 0.087 & 0.087 & 0.117 & 0.125 & 0.117 & 0.122 & 0.125 & 0.132 \\
& & & & & & & & & \\
Total value & 0.366 & 0.371 & 0.394 & 0.439 & 0.460 & 0.471 & 0.484 & 0.494 & 0.521 \\
\hline
\end{tabular}

The unsupervised Principal Component Analysis (PCA), a multivariate analysis method for visualization of similarities or differences among data groups, is applied for the data analysis on Table 6. Fig. 10 illustrates the result of the PCA score plots of three groups.

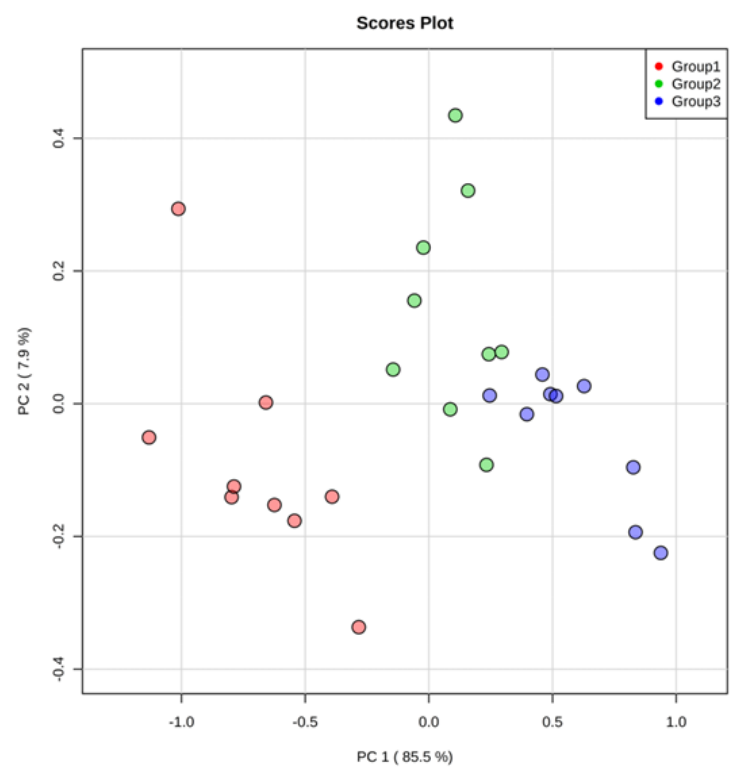

Fig. 10. PCA score plot of three groups.

The contributions of two principal components (PC 1 and PC 2) equal 85.5\% and 7.9\% of the variation, respectively. They show a clear classification trend of three groups and demonstrate that the three groups are simultaneously visible to be distinguished. This is a prerequisite for demonstrating that the four parameters can be employed to distinguish the 
three groups. In order to select the most effective roughness parameter from the four roughness parameters, Random Forest is employed to identify and rank the importance of four roughness parameters in the three groups.

Fig. 11 illustrates the relative importance of four roughness parameters by means of Random Forest.

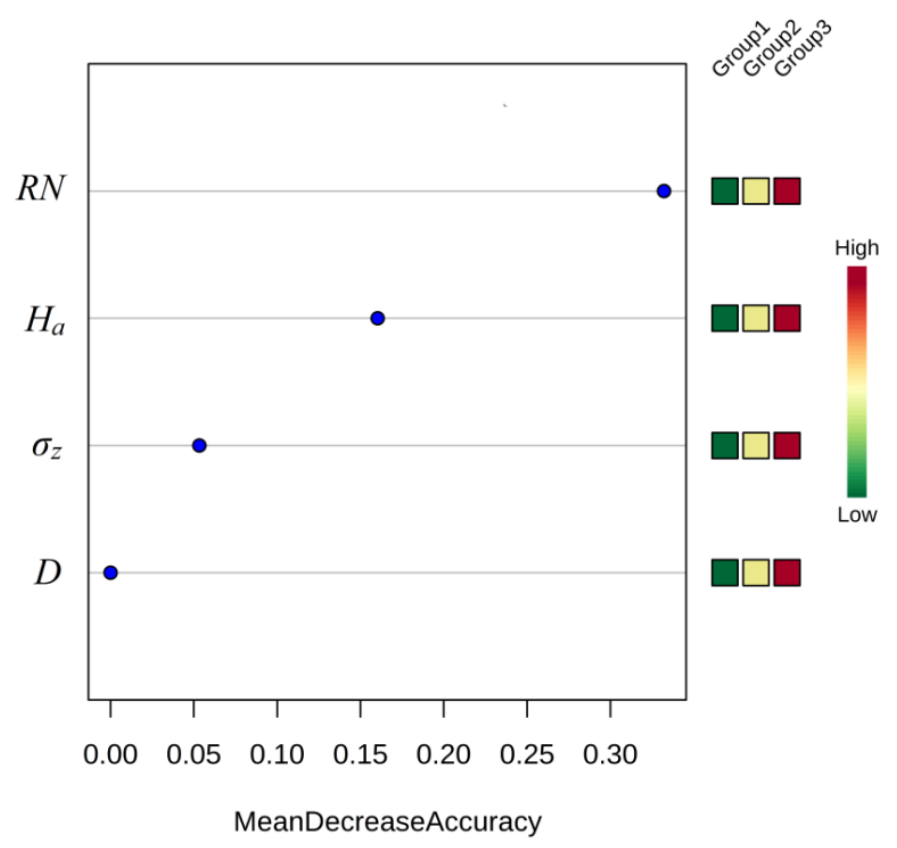

Fig. 11. Importance of four roughness parameters by Random Forest.

From Fig. 11, the MeanDecreaseAccuracy value of four roughness parameters is in an order of $R N>H_{a}>\sigma_{z}>D$. This means that the $R N$ is the most effective roughness parameter for the evaluation of roughness of fractured concrete surface.

\subsection{Comparison of the roughness parameter $R N$ of different samples}

A comparison of $R N$ of fractured surfaces is shown in Fig. 12, and the results are summarized as follows: 


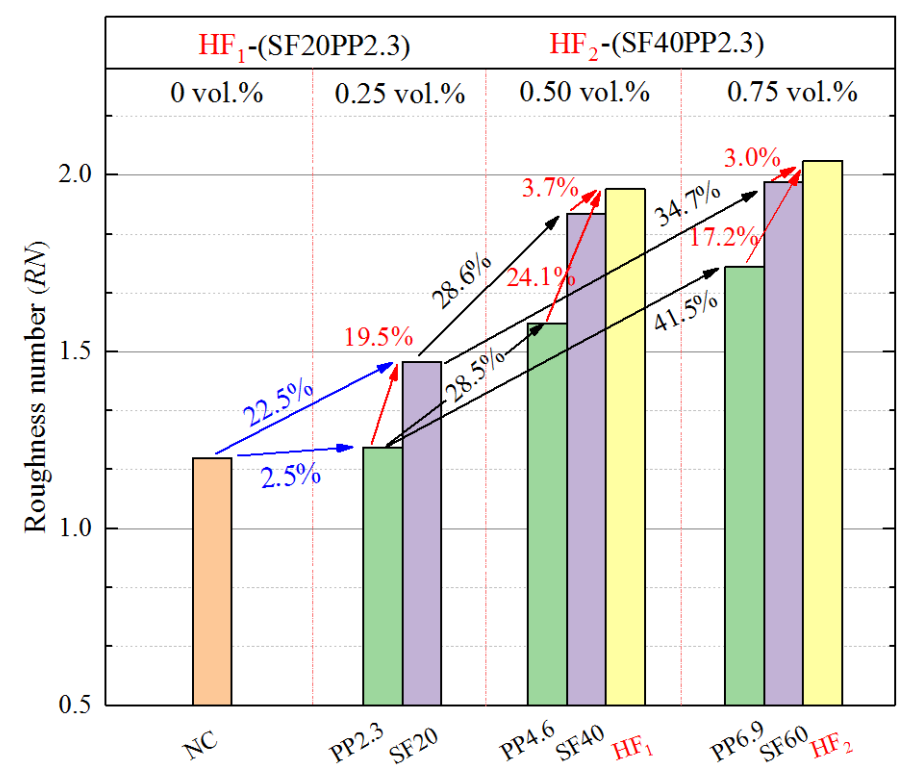

Fig.12. Comparison of the roughness parameter $R N$ of different samples

1. Compared to the NC, the $R N$ parameter of PP2.3 and SF20 increase about $2.5 \%$ and $22.5 \%$, respectively. With the increasing of fiber content, the crack roughness parameter $R N$ increases.

2. For PFRC, the $R N$ increases with the increasing of PP fiber content. As compared to the PP2.3, further increases of $28.5 \%$ and $41.5 \%$ were observed on the samples with $4.6 \mathrm{~kg} / \mathrm{m}^{3}$ (PP4.6) and $6.9 \mathrm{~kg} / \mathrm{m}^{3}$ (PP6.9) fiber additions, respectively.

3. For SFRC, the same trend could be identified. As compared to the SF20, about $28.6 \%$ and $34.7 \%$ increments of $R N$ could be reached by the addition of $40 \mathrm{~kg} / \mathrm{m}^{3}$ (SF40) and $60 \mathrm{~kg} / \mathrm{m}^{3}$ (SF60) steel fibers, respectively.

4. For the hybrid fiber $(\mathrm{PP}+\mathrm{SF})$ reinforcement, there are three variables in the system (PP content, steel fiber content and their proportions), the above mentioned trend could still be identified if one fiber content was kept constant, e.g. all studied samples with the 2.3 $\mathrm{kg} / \mathrm{m}^{3}$ PP fiber content. As compared to the PP2.3 $\left(0 \mathrm{~kg} / \mathrm{m}^{3} \mathrm{SF}+2.3 \mathrm{~kg} / \mathrm{m}^{3} \mathrm{PP}\right)$, the roughness parameter $R N$ of SF20PP2.3 $\left(20 \mathrm{~kg} / \mathrm{m}^{3} \mathrm{SF}+2.3 \mathrm{~kg} / \mathrm{m}^{3} \mathrm{PP}\right)$ and SF40PP2.3 
$\left(40 \mathrm{~kg} / \mathrm{m}^{3} \mathrm{SF}+2.3 \mathrm{~kg} / \mathrm{m}^{3} \mathrm{PP}\right)$ increase by about $59.3 \%$ and $65.9 \%$, respectively.

5. In general, roughness $R N$ of hybrid fiber reinforced concrete (HFRC) is much higher than that of mono fiber reinforced concrete (SFRC and PFRC) with the same volume content of fibers.

a) For specimens with 0.5 vol.\% of fiber content, as compared to the PP4.6 and SF40 specimens, the roughness parameter $R N$ of SF20PP2.3 increases by about $24.1 \%$ and $3.7 \%$, respectively.

b) For specimens with 0.75 vol.\% of fiber content, as compared to the PP 6.9 and SF60 specimens, the roughness parameter $R N$ of SF40PP2.3 increases by about $17.2 \%$ and $3.0 \%$, respectively.

Overall, $R N$ derived from topographical study could be applied to the analysis of fractured surface roughness of the concrete. With the increasing of fiber content, the roughness of cracked surface increases and the increase rate of cracked surface roughness decreases, which shows an exponent-like relation and will be explained in the following section, and this trend is consistent with the reported data . Threshold may exist but it didn't show in the current investigation. For hybrid fiber reinforcement (HFRC), the roughness of fractured surface is generally higher than that of mono fiber reinforced concrete at the same fiber volume content.

In the previous reported studies ${ }^{[36,37]}$, the roughness of fractured surface of plain concrete had a direct relationship with size and content of coarse aggregate. For FRC, the fibers in concrete matrix play a significant role on the crack trajectory and surface roughness. Armandei et al. ${ }^{[38]}$ analyzed the effect of fiber on the fractured surface, and the result suggested that the fibers, aggregates and paste of FRC form some "colonies" (see Fig. 13), which may exhibit higher local tensile strength than that of aggregates and pastes, it causes that the cracks can be prevented to propagate into the "colonies" and deviated the trajectory path of crack toward the interval of the "colonies" (Fig. 13 (b)). The fiber and paste of "colonies" work together like a strong "armor" wrapped around the aggregate, and the size of 
"colonies" is larger than that of aggregate. It is known that the roughness of fractured surface gradually increases with the increasing of size of aggregate ${ }^{[39]}$, so the "colonies" cause rougher fractured surface than the aggregates. This may explain a much rough surface on the fractured concrete with fibers reinforcement. With increment of fiber content, the domain of "colonies" in FRC matrix expands, which leads to an increment of the roughness of fractured surface. Meanwhile, the high content of fiber could also cause much tortuous trajectory of the cracks.

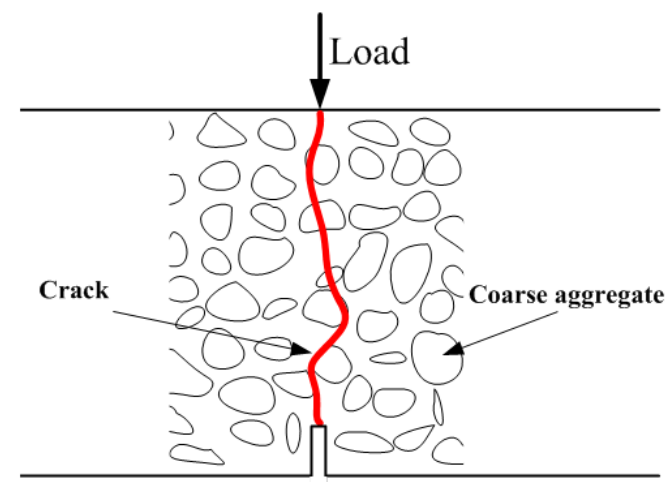

(a)

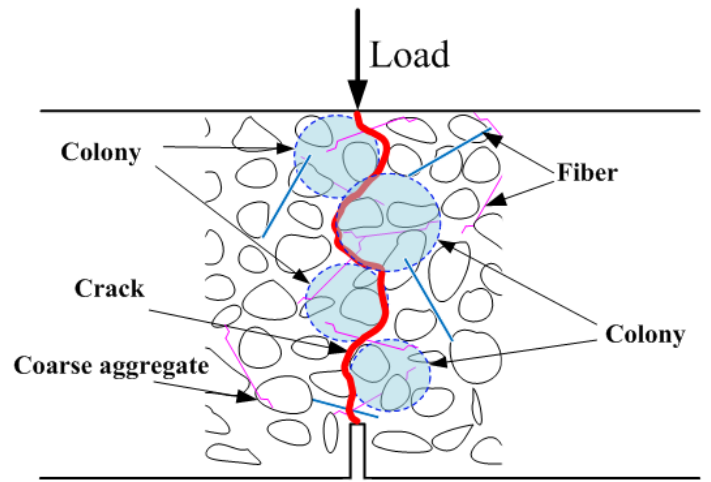

(b)

Fig. 13. Schematic of the crack propagation

(a) Normal concrete ; (b) Fiber reinforced concrete.

\subsection{Relationship between the roughness of fractured surface and the flexural toughness} parameters

The roughness parameter $R N$ of the fractured concrete was further correlated to the evaluation of flexural toughness of the concrete $\left(\mathrm{f}_{\mathrm{eq}, 2}, \mathrm{f}_{\mathrm{eq}, 3}, \mathrm{~F}_{2}\right.$ and $\left.\mathrm{F}_{3}\right)$, as shown in Fig. 14 (a)-(d). 0.25 vol.\% (e.g. PP2.3 and SF20), 0.5 vol.\% (e.g. PP4.6 and SF40) and 0.75 vol.\% (e.g. PP6.9 and SF60) of fiber contents were used for PFRC and SFRC specimens. PP2.3 (0 $\left.\mathrm{kg} / \mathrm{m}^{3} \mathrm{SF}+2.3 \mathrm{~kg} / \mathrm{m}^{3} \mathrm{PP}\right), \mathrm{SF} 20 \mathrm{PP} 2.3\left(20 \mathrm{~kg} / \mathrm{m}^{3} \mathrm{SF}+2.3 \mathrm{~kg} / \mathrm{m}^{3} \mathrm{PP}\right)$ and SF40PP2.3 $\left(40 \mathrm{~kg} / \mathrm{m}^{3}\right.$ $\mathrm{SF}+2.3 \mathrm{~kg} / \mathrm{m}^{3} \mathrm{PP}$ ) were considered for the investigation of HFRC. 
In Fig. 14, it can be seen that the relationships between the roughness parameter $R N$ of fractured surface and the flexural toughness parameters $\left(\mathrm{f}_{\mathrm{eq}, 2}, \mathrm{f}_{\mathrm{eq}, 3}, \mathrm{~F}_{2}\right.$ and $\left.\mathrm{F}_{3}\right)$ correspond well with exponent functions, which can be expressed in following Eq. (7):

$$
Y=m \cdot \exp (X / n)+p
$$

where $m, n$ and $p$ are the parameters fitted corresponding to the experiment, the variable $X$ is the roughness parameter $R N$ of fractured surface and the $Y$ is the flexural toughness parameters $\left(\mathrm{f}_{\mathrm{eq}, 2}, \mathrm{f}_{\mathrm{eq}, 3}, \mathrm{~F}_{2}\right.$ and $\left.\mathrm{F}_{3}\right)$, respectively.

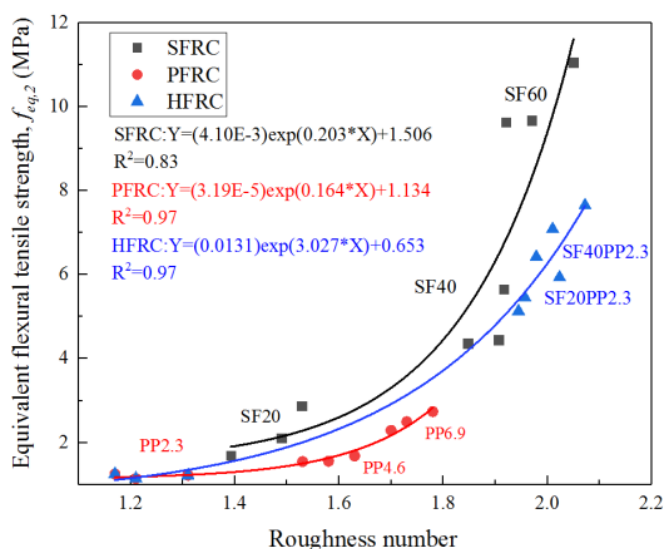

(a)

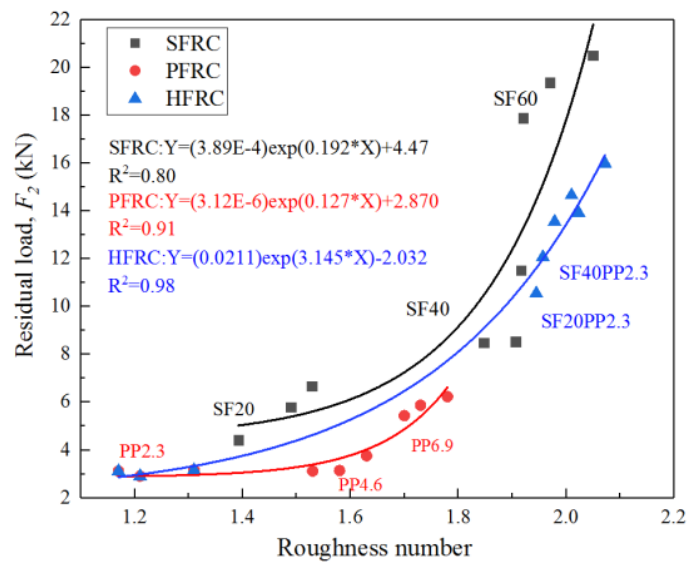

(c)

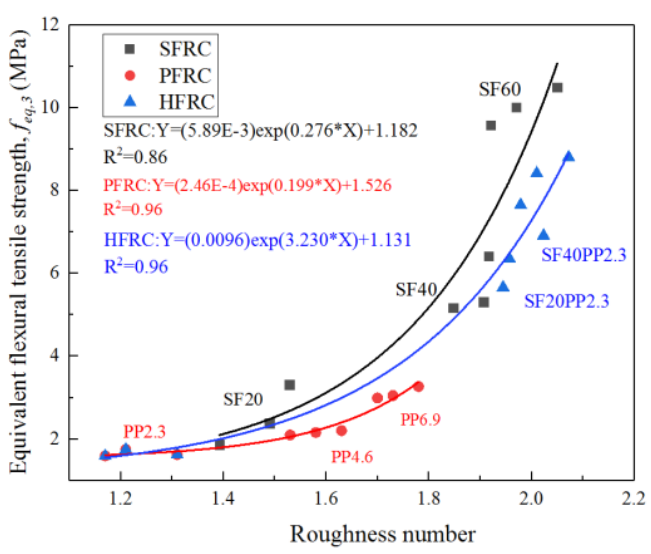

(b)

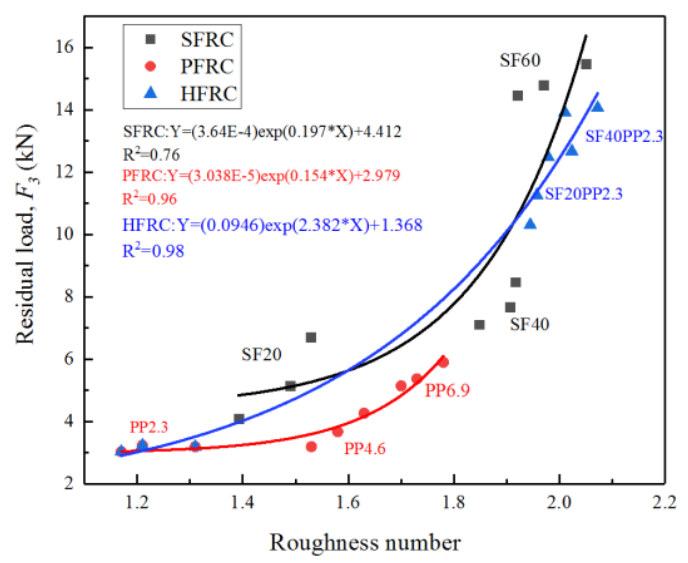

(d)

Fig.14. Relationship between parameters of flexural toughness and fractured surface roughness

(a) $\mathrm{f}_{\mathrm{eq}, 2^{-}}$-roughness number; (b) $\mathrm{f}_{\text {eq } 3^{-}}$roughness number; (c) $\mathrm{F}_{2^{-}}$-roughness number; (d) $\mathrm{F}_{3^{-}}$ 
roughness number.

From Fig. 14, it can be seen that the flexural toughness of PFRC, SFRC and HFRC beams presents an exponential growth with increment of roughness parameter $R N$. The exponential function between flexural toughness and $R N$ roughness was further confirmed by the published data ${ }^{[40][41]}$, this indicates the general applicability of the proposed function. One of the reasons maybe trace back to the numbers of fiber on the fractured surface. The roughness of fractured surface increases with the increasing of fiber dosage, and increasing roughness of fractured surface causes the surface area of crack to become large and the number of fibers of bridging cracks to increase. When the fibers in FRC are uniformly distributed three-dimensionally in the beams, the number of fibers of bridging cracks is determined by the fiber dosage and the surface area of crack. With increment of fiber dosage, the roughness of fractured surface increase and it leads to an increment of surface area of crack simultaneously, so it may be the reason that the increase rate of the number of fibers of bridging cracks is higher than the increase rate of fiber dosage. This leads to a rapid increment of the flexural toughness of beams with the increasing of fiber dosage (see Table 4). Meanwhile, the increase rate of fractured surface roughness decreases with increment of fiber dosage (see Fig. 12). Therefore, the relationships between the roughness of fractured surface and the flexural toughness agree with the exponent functions rather than the linear functions.

The parameters fitted of Eq. (7) maybe vary depending on the properties of fiber and concrete mix design. Moreover, the functions between flexural toughness and roughness of crack surface can be considered as a tool box to estimate quickly and conveniently the roughness of crack surface by means of the flexural toughness of FRC according to RILEM TC162-TDF $^{[34]}$. This paper presents a pioneer work in this field. Future study will focus on combining the result in this paper and previous investigations ${ }^{[5,6,28,30]}$ of the relationships between the between crack geometry and permeability, and they will provide the theoretical support of the study between the durability (water/gas permeability) and mechanical behavior of cracked fiber reinforced concrete. 


\section{Conclusions}

This study proposed a topographical analysis of the fractured surface feature and its correlation to the flexural toughness of FRC, the following conclusions can be drawn:

1. The custom-built 3-D laser scanning equipment was able to be applied to acquire the topographical information of fractured surface of FCR, and the topographical analysis results could be quantitatively represented by the roughness parameters of roughness number $(R N)$, fractal dimension $(D)$, standard deviation of height distribution $\left(\sigma_{z}\right)$, and arithmetic mean deviation of the surface topography $\left(H_{a}\right)$, respectively.

2. The multivariate analysis is applied to the topographical analysis of the concrete fractured surface, and it is proven to be useful for evaluating the significance of different roughness parameters. The roughness number $R N$ demonstrates the most significant during the evaluation.

3. For FRC, the exponent function agrees well with the relationships between the roughness of surface and the flexural toughness. Such relationships can be employed to estimate the roughness of crack surface by means of the flexural toughness and then to provide the theoretical support for predicting the durability of FRC.

4. Synergetic effect was confirmed to significantly improve the flexural behavior and the roughness of fractured surface of the concrete by using hybrid fiber, as compared to the SFRC and PFRC specimens.

\section{Acknowledgment}

The authors acknowledge the National Natural Science Foundation of China (Grant: $51578109)$ 


\section{References:}

[1] Weerheijm J, Reinhardt HW. Device for testing concrete under impact tensile loading and lateral compression. Nuclear Engineering \& Design. 1991;126(3): 395-401.

[2] Erdem S, Blankson MA. Fractal - fracture analysis and characterization of impact-fractured surfaces in different types of concrete using digital image analysis and 3D nanomap laser profilometery. CONSTR BUILD MATER. 2013;40: 70-6.

[3] Kumar S, Barai SV. Concrete Fracture Models and Applications. 2011.

[4] Issa MA, Issa MA, Islam MS, Chudnovsky A. Fractal dimension - a measure of fracture roughness and toughness of concrete. ENG FRACT MECH. 2003;70(1): 125-37.

[5] Rastiello G, Boulay C, Dal Pont S, Tailhan JL, Rossi P. Real-time water permeability evolution of a localized crack in concrete under loading. CEMENT CONCRETE RES. 2014;56: 20-8.

[6] Ding Y, Li D, Zhang Y. Quantitative analysis of macro steel fiber influence on crack geometry and water permeability of concrete. COMPOS STRUCT. 2018;187: 325-35.

[7] Holzer LPHA. Cryo - FIB - nanotomography for quantitative analysis of particle structures in cement suspensions. J MICROSC-OXFORD. 2007;227(3): 216-28.

[8] Erdem S, Dawson AR, Thom NH. Micromechanical Structure-Property Relationships for the Damage Analysis of Impact-Loaded Sustainable Concrete. J MATER CIVIL ENG. 2012;5(25): 597-609.

[9] Dalibor ME, Hana D. Registration of Partially Focused Images for 2D and 3D Reconstruction of Oversized Samples. SCANNING. 2017;2017(1): 1-8.

[10] Tafti AP, Kirkpatrick AB, Alavi Z, Owen HA, Yu Z. Recent advances in 3D SEM surface reconstruction. MICRON. 2015;78: 54-66.

[11] Yan S, Adegbule A, Kibbey TCG. A hybrid 3D SEM reconstruction method optimized for complex geologic material surfaces. MICRON. 2017;99: 26.

[12] Limandri S, Galván Josa V, Valentinuzzi MC, Chena ME, Castellano G. 3D scanning electron microscopy applied to surface characterization of fluorosed dental enamel. MICRON. 2016;84: 54-60.

[13] Ficker, T. Sectional techniques for 3D imaging of microscopic and macroscopic objects. OPTIK. 2017;144: 289-99.

[14] Ficker T, Marti Ek D. Three-dimensional reconstructions of solid surfaces using conventional 
microscopes. SCANNING. 2016;38(1): 21-35.

[15] Ficker T, Martišek D. Digital fracture surfaces and their roughness analysis: Applications to cement-based materials. Cement \& Concrete Research. 2012;42(6): 827-33.

[16] Yunbiao Xin KJH. Quantitative characterization of the fracture surface of Si single crystals by confocal microscopy. J AM CERAM SOC. 1995;78(12): 3201-8.

[17] Ficker T, Martišek D. Roughness and fractality of fracture surfaces as indicators of mechanical quantities of porous solids. Central European Journal of Physics. 2011;9(6): 1440-5.

[18] Ficker T, Martišek D, Jennings HM. Roughness of fracture surfaces and compressive strength of hydrated cement pastes. CEMENT CONCRETE RES. 2010;40(6): 947-55.

[19] Lange DA, Ouyang C, Shah SP. Behavior of cement based matrices reinforced by randomly dispersed microfibers. Advanced Cement Based Materials. 1996;1(3): 20-30.

[20] Apedo KL, Montgomery P, Serres N, Fond C, Feugeas F. Geometrical roughness analysis of cement paste surfaces using coherence scanning interferometry and confocal microscopy. MATER CHARACT. 2016;118: 212-24.

[21] Zampini D, Jennings HM, Shah SP. Characterization of the paste-aggregate interfacial transition zone surface roughness and its relationship to the fracture toughness of concrete. J MATER SCI. 1995;30(12): 3149-54.

[22] Lange DA, Jennings HM, Shah SP. Relationship between Fracture Surface Roughness and Fracture Behavior of Cement Paste and Mortar. J AM CERAM SOC. 1993;76(3): 589-97.

[23] Cai W, Cen G, Wang H. Fracture Surface Fractal Characteristics of Alkali-Slag Concrete under Freeze-Thaw Cycles. ADV MATER SCI ENG. 2017;2017: 1-9.

[24] Carpinteri A. A fractal analysis of size effect on fatigue crack growth. INT J FATIGUE. 2004;26(2): 125-33.

[25] Brown SR. Fluid flow through rock joints: The effect of surface roughness. Journal of Geophysical Research Solid Earth. 1987;92(B2): 1337-47.

[26] Mandelbrot BB. The fractal geometry of nature 1982.

[27] Abell AB, Lange DA. Fracture mechanics modeling using images of fracture surfaces. 1998;35(31-32): 4025-33.

[28] Akhavan A, Shafaatian S, Rajabipour F. Quantifying the effects of crack width, tortuosity, and roughness on water permeability of cracked mortars. CEMENT CONCRETE RES. 2012;42(2): 313-20. 
[29] Mechtcherine V, Lieboldt M. Permeation of water and gases through cracked textile reinforced concrete. Cement and Concrete Composites. 2011;33(7): 725-34.

[30] Picandet V, Khelidj A, Bellegou H. Crack effects on gas and water permeability of concretes. CEMENT CONCRETE RES. 2009;39(6): 537-47.

[31] Common portland cement GB175-2007. 2007.

[32] ASTM C143. Standard test method for slump of hydraulic-cement concrete, ASTM International: West Conshohocken, 2012.

[33] ASTM C231/C231M-09b. Standard test method for air content of freshly mixed concrete by the pressure method. Annual Book of ASTM Standards, vol.04.02. Philadelphia (USA): American Society for Testing and Materials; 2010..

[34] Rilem Tc. 162-TDF: test and design methods for steel fiber reinforced concrete- bending test. MATER STRUCT. 2002(35): 579-82.

[35] Zhou HW, Xie H. Direct Estimation of the Fractal Dimensions of a Fracture Surface of Rock. Surface Review \& Letters. 2003;10(05): 751-62.

[36] Yu, Q., Size Effect in Fracture of Concrete Specimens and Structures: New Problems and Progress. Acta Polytechnica 2004;44: 5-6.

[37] Bažant ZP. Probabilistic modeling of quasibrittle fracture and size effect. Principal Plenary Lecture 2001: 1-23.

[38] Armandei M, de Souza Sanchez Filho E. Correlation between fracture roughness and material strength parameters in SFRCs using 2D image analysis. CONSTR BUILD MATER. 2017;140 : 82-90.

[39] Yan A, Wu K, Zhang D, Yao W. Effect of fracture path on the fracture energy of high-strength concrete. CEMENT CONCRETE RES. 2001;31(11): 1601-6.

[40] Kurtis KE, El-Ashkar NH, Collins CL, Naik NN. Examining cement-based materials by laser scanning confocal microscopy. Cement \& Concrete Composites 2003;25(7): 695-701.

[41] Ding Y. Investigations into the relationship between deflection and crack mouth opening displacement of SFRC beam. CONSTR BUILD MATER. 2011;25(5): 2432-40. 